\title{
Method Based on Rough Set and Improved Petri Net for Transformer Fault Diagnosis
}

\author{
http://dx.doi.org/10.3991/ijoe.v11i8.4879 \\ Chengyu Sun ${ }^{1}$ XiaoGuang Yue ${ }^{2}$ \\ ${ }^{1}$ Jilin Institute of Chemical and Technology, Jilin City, P. R. China \\ ${ }^{2}$ Wuhan University, Wuhan, P. R. China
}

\begin{abstract}
Oil chromatographic analysis is widely used in transformer fault diagnosis, but it is difficult to establish accurate mapping relationships between the parameter space and the state space, and there is information complexity. This paper adopts the combined diagnostic model of rough sets and Petri networks. It first simplifies the complex system that contains complicated discrete information through a rough set to solve the state space limitations of a Petri network and improve the petri network based on mining association rules. It adopts a correlation matrix and state equation method to improve the reasoning speed and, at the same time, turns the diagnosis into matrix operations to change the complex calculations to simple math, which has certain applicability. Finally, the algorithm is applied to gas chromatographic analysis in transformer oil; the calculation results are the same with an IEC three ratio method, which proves that this method can quickly and accurately judge the running state of a transformer to improve the safety, stability and economic operation of a flat water transformer.
\end{abstract}

Index Terms-rough set, improved Petri net, gas chromategraph analysis.

\section{INTRODUCTION}

Oil chromatographic analysis (DGA) is the main method for status detection and fault diagnosis of a transformer. Based on study and analysis of existing international technologies, reducing a status detection and diagnostic system's complexity, increasing the information collected by the system, and obtaining the optimization balance between the two are the development trends of online monitoring of power transformers, which is key to improving a system's performance. In China, transformer fault diagnosis technology is mainly based on experimental data, using artificial intelligence and expert systems. Castro applied fuzzy theory to fault pattern recognition and information recognition to deal with the uncertain and incomplete information and data effectively. Racoceanu presented a new fault diagnosis method for transformers. Although to a certain extent it can solve the contradiction between diagnosis system complexity and the system acquisition information, it is still difficult to map relationships between the high dimensional information parameter space and the state space.

This paper combines rough set theory and an improved Petri network, applies a rough set to the effective reduction of monitoring information, uses an improved Petri network to conduct diagnostic analysis, and applies this method to the complex changes in transformer fault diagnosis.

\section{ROUGH SET THEORY SUMMARY}

Rough set refers to sample sets $\left\{\mathrm{x}_{1}, \mathrm{x}_{2}, \ldots, \mathrm{x}_{\mathrm{n}}\right\}$, sample attribute sets, and attribute range systems as the information system, expressed as A. If the attribute set can be divided into the condition attribute set $\mathrm{L}$ and decision attribute set $\mathrm{D}$, a decision system can be constructed as rough set constructs sample data in the form of tables, in which the rows represent sample individuals and the columns represent attributes. This table can be called a decision table, which is the expression of a decision system form. When it comes to pattern classification problems, we refer to conditional attributes as discrimination factors, and decision attributes present categories of sample individuals. Classification is used to determine the individual category by the individual condition attribute values, namely the decision attribute values.

According to the collected data and information, we established a multiple attribute information system, used rough set theory to deal with the decision table, and then, according to the following steps, created a vertical reduction of a decision table:

a. Deleting the repeated rules in the table;

b. Eliminating redundant condition attributes in the table;

c. Reducing the decision rule, that is deleting redundant attributes of the classification rules;

d. Minimizing decision-making algorithms further and removing redundant decisions from the simplified decision-making table;

e. Deciding activities based on the decision rules we have found.

Through the above process, we can reset the remaining properties, simplify them on the horizontal level, calculate the attribute's importance, and obtain a reduced set of decision tables.

\section{IMPROVED PETRI NET METHOD}

\section{A. Traditional Petri Net}

Petri net is an important theory in the field of fault diagnosis, mainly including place, transition, and arc. It represents a system model by net graphs to describe parallel or sequential system events. In the complex system model, a Petri net is applied when a model state space complexity problem exists, appearing as it increases exponentially with the increase of actual system size. In addition, a traditional Petri net has problems such as conflict, collision, and a deadlock. 


\section{B. Improved Petri Net}

An Improved Petri Net (IPN) is necessary to adapt to the process and results of the transformer state change events, and the traditional Petri net is redefined.

The form of a decision table with an Improved Petri Net is as follows:

$$
\mathrm{A}=(\mathrm{P}, \mathrm{T}, \mathrm{E}, \mathrm{J}, \mathrm{W}, \mathrm{G}, \mathrm{M}, \mathrm{U})
$$

Here $\mathrm{P}$ represents the event set, $\mathrm{T}$ represents the event change set, event set, and change sets, respectively: $\mathrm{P}=\left\{\mathrm{P}_{\mathrm{i}}\right\},(\mathrm{i}=1,2, \ldots, \mathrm{n})$ and $\mathrm{T}=\left\{\mathrm{t}_{\mathrm{j}}\right\},(\mathrm{j}=1,2, \ldots, \mathrm{m})$. E represents the transfer event, which is related to the events change caused by different event symptoms. A Petri Net library indicates an abnormal state when the token is 1 , otherwise normal.

$\mathrm{J}$ represents the capacity function, with the form of $\mathrm{P} \rightarrow$ $(0,1) . \mathrm{W}=\left\{\mathrm{w}_{\mathrm{i}}\right\}(\mathrm{i}=1,2, \ldots, \mathrm{n})$ is the weight function, $\forall \mathrm{w}_{\mathrm{i}} \in$ $\mathrm{W}: \mathrm{w}_{\mathrm{i}}=1$.

$G$ represents the time stamp set for change, $G_{j}(n)$ represents that the change $G_{j}$ ignites at the moment of after ignition, $\mathrm{G}=\mathrm{G}+\left\{\mathrm{G}_{\mathrm{j}}(\mathrm{n})\right\}$. Introducing the time stamp set of change can identify the event propagation path and at the same time prevent the ignition of change repeatedly.

$M$ represents the change time tag set. $\mathrm{M}_{0}=\left\{\mathrm{M}_{0}\left(\mathrm{P}_{1}\right)\right.$, $\left.\mathrm{M}_{0}\left(\mathrm{P}_{2}\right), \ldots, \mathrm{M}_{0}\left(\mathrm{P}_{\mathrm{n}}\right)\right\}$ is called the initial identification, which represents the distribution of an abnormal state in the system. In the development of an abnormal state in the system, each time change is identified as $\mathrm{M}_{1}, \mathrm{M}_{2}, \ldots, \mathrm{M}_{\mathrm{end}}$.

For the Petri Net, the correlation matrix $\mathrm{V}=\left[\mathrm{V}_{\mathrm{ij}}\right]$ is as follows:

$$
\mathrm{M}_{\mathrm{k}+1}=\mathrm{M}_{\mathrm{k}} \oplus(\mathrm{V} \otimes \mathrm{U})
$$

Where $M_{k}, M_{k+1}$, respectively, represent the initial marking set and result set for the change ignition at the $\mathrm{K}$ moment; $U$ represents the transition firing sequence at the $\mathrm{K}$ moment, which is an $\mathrm{m}$ column matrix composed of 0 and 1 . To make the state equation comply with the event propagation characteristics, it introduces an identity operator" $\oplus$ "and" $\otimes$ ".

$$
\begin{aligned}
& \forall \mathrm{a}, \mathrm{b}, \mathrm{u} \in \mathrm{R}^{1 \times \mathrm{n}}: \mathrm{u}=\mathrm{a} \oplus \mathrm{b}, \mathrm{so}: \\
& \qquad u_{\mathrm{i}}=\mathrm{v}\left(\mathrm{a}_{\mathrm{i}}, \mathrm{b}_{\mathrm{i}}\right), 1 \leq \mathrm{i} \leq \mathrm{n}
\end{aligned}
$$

Where operator " $\mathrm{v}$ " takes the maximum value symbol. "๑ "is the logical and operator symbol, which means that the value of $v$ depends on the parameters of a and $b$. When $\mathrm{a}$ and $\mathrm{b}$ are within 0 and 1 , the value range of $u$ is $\{0,1\}$.

$$
\forall \mathrm{V} \in \mathrm{R}^{\mathrm{n} \times \mathrm{m}}, \mathrm{U} \in \mathrm{R}^{\mathrm{n} \times 1}, \mathrm{So}:
$$

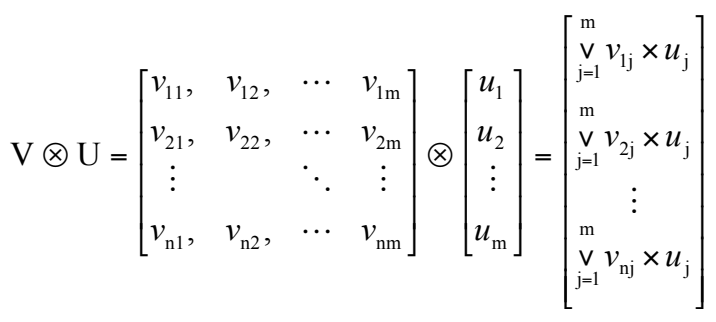

" $\otimes "$ is the logical multiplication operator symbol, which means the system state value may only transfer in the associated event. By introducing the identity operator, the complicated matrix operation can be transferred into logic operations or the addition operation, which simplifies the process of calculation.

\section{EXAMPLES}

There are running records of power transmission and transformation equipment in a certain area from longitudinal and transverse statistics. This is part of the value shown in Table I. Traditional fault analysis adopts a three ratio method, the diagnosis results of which have small deviation from the actual fault. By a three ratio calculation, the corresponding fault state of each sample data can be obtained.

TABLE I.

DETECTED FAULT DATA

\begin{tabular}{|c|c|c|c|c|c|c|c|c|l|}
\hline \multirow{2}{*}{ No. } & \multicolumn{7}{|c|}{ Fault feature parameters $(\boldsymbol{\mu L} \mathbf{L}-\mathbf{1})$} & \multirow{2}{*}{ Fault state } \\
\cline { 2 - 10 } & $\mathbf{H 2}$ & $\boldsymbol{C H 4}$ & $\mathbf{C 2 H} \mathbf{6}$ & $\boldsymbol{C 2 H 4}$ & $\boldsymbol{C 2 H 2}$ & $\boldsymbol{C O}$ & $\boldsymbol{C O 2}$ & $\begin{array}{c}\text { Total } \\
\text { hydrocarbon }\end{array}$ & \\
\hline 1 & 147.20 & 20.70 & 10.90 & 76.00 & 6.00 & 220.80 & 2047.80 & 113.60 & High temperature overheat \\
\hline 2 & 19.00 & 431.00 & 214.00 & 772.00 & 0.00 & 996.00 & 2087.00 & 1417.00 & High temperature overheat \\
\hline 3 & 15.30 & 35.49 & 20.50 & 118.43 & 7.30 & 421.87 & 4769.60 & 182.17 & High temperature overheat \\
\hline 4 & 25.60 & 142.80 & 339.90 & 82.60 & 1.50 & 451.00 & 931.00 & 566.80 & Low temperature overheat \\
\hline 5 & 26.10 & 162.30 & 370.60 & 88.80 & 1.60 & 765.60 & 2241.00 & 623.30 & Low temperature overheat \\
\hline 6 & 47.90 & 5.20 & 2.90 & 54.80 & 1.70 & 366.50 & 4374.80 & 64.60 & Low temperature overheat \\
\hline 7 & 112.00 & 93.30 & 32.00 & 123.60 & 0.50 & 147.60 & 471.00 & 245.60 & Middle temperature overheat \\
\hline 8 & 179.00 & 323.00 & 184.00 & 393.00 & 0.00 & 1032.00 & 2415.00 & 899.00 & Middle temperature overheat \\
\hline 9 & 218.00 & 120.70 & 26.60 & 142.10 & 0.90 & 230.00 & 1066.00 & 289.00 & Middle temperature overheat \\
\hline 10 & 141.00 & 131.00 & 13.00 & 139.00 & 19.00 & 513.00 & 1558.00 & 302.00 & Low energy discharge \\
\hline 11 & 30.10 & 17.10 & 2.20 & 5.50 & 5.20 & 596.00 & 1186.00 & 30.00 & Low energy discharge \\
\hline 12 & 44.30 & 21.50 & 7.10 & 98.70 & 76.70 & 288.60 & 2761.00 & 204.00 & Low energy discharge \\
\hline 13 & 198.00 & 39.00 & 7.10 & 27.00 & 22.50 & 240.00 & 1468.00 & 95.60 & Low energy discharge \\
\hline 14 & 410.00 & 32.99 & 2.59 & 24.79 & 191.15 & 406.00 & 1519.00 & 284.51 & High energy discharge \\
\hline 15 & 86.13 & 31.82 & 8.58 & 8.52 & 21.05 & 564.48 & 4536.00 & 69.97 & High energy discharge \\
\hline
\end{tabular}


The key of a three ratio method is to compare the absolute value of each gas in the sample data to analyze the gas/oil ratio in different failure modes based on the angle of relative change. The main objects of analysis are the hydrogen and hydrocarbon gases. Although there are changes in the ingredients of the carbon and oxygen compounds, the impacts on the fault condition are not obvious. The reasoning model is not sufficient, so it is often expressed by expert experiences and other forms of representation in the knowledge system.

\section{A. Optimization of parameters in condition monitoring}

Based on the different working conditions of the monitoring transformers, samples of different status can be found. Through a trend discretization algorithm, we set the decision table as shown in Table II. Among them, the condition attribute is $\mathrm{L}=\left\{l_{\mathrm{j}}\right\}, 1 \leq \mathrm{j} \leq 5$, respectively, presenting hydrogen $l_{1}$, hydrocarbon gases (including total hydrocarbon) $l_{2-6}$; the decision attribute is $\mathrm{D}=\left\{\mathrm{d}_{\mathrm{j}}\right\}, 1 \leq \mathrm{j} \leq 5$, respectively, representing an overheating fault $\left(\mathrm{Q}_{1} \leq 300^{\circ} \mathrm{C}\right.$, $300<\mathrm{Q}_{2} \leq 700^{\circ} \mathrm{C}, \mathrm{Q}_{3}>700^{\circ} \mathrm{C}$ ), and a discharge fault (low energy discharge $F_{1}$, high energy discharge $F_{2}$ ). The limit values of the hydrogen and hydrocarbon gases are referred [9].

In accordance with the reduction step for the decision table, we calculated the significance of the attributes to find the core of the decision table, said $\left\{\mathrm{c}_{1}, \mathrm{c}_{2}, \mathrm{c}_{4}, \mathrm{c}_{5}\right\}$. To avoid the missing of part of the association rules during the reduction process, we chose $\left\{l_{1}, l_{2}, l_{4}, l_{5}, l_{6}\right\}$ as the measurement parameters set, i.e. hydrogen, methane, ethylene, acetylene, and total hydrocarbon, because there is a certain indiscernibility relation among carbon and oxygen compounds and other gases. The importance is not high about the fault status. The measurement parameter set is not exclusive; the fault state space and parameter space should construct reasonable mapping combined with the actual situation.

TABLE II.

TYPE SIZES FOR CAMERA-READY PAPERS

\begin{tabular}{|c|c|c|c|c|c|c|c|}
\hline \multirow{2}{*}{ No. } & \multicolumn{6}{|c|}{ Condition attribute } & \multirow{2}{*}{$\begin{array}{c}\text { Decision attributes } \\
\text { D }\end{array}$} \\
\hline & $\overline{l_{1}}$ & $l_{2}$ & $l_{3}$ & $l_{4}$ & $l_{5}$ & $l_{6}$ & \\
\hline 1 & 2 & 2 & 2 & 3 & 3 & 2 & $\mathrm{Q}_{3}$ \\
\hline 2 & 1 & 5 & 4 & 5 & 1 & 5 & $\mathrm{Q}_{3}$ \\
\hline 3 & 1 & 2 & 2 & 4 & 3 & 3 & $\mathrm{Q}_{3}$ \\
\hline 4 & 1 & 4 & 5 & 3 & 2 & 4 & $\mathrm{Q}_{1}$ \\
\hline 5 & 1 & 4 & 5 & 3 & 2 & 4 & $\mathrm{Q}_{1}$ \\
\hline 6 & 1 & 1 & 1 & 2 & 2 & 2 & $\mathrm{Q}_{1}$ \\
\hline 7 & 2 & 3 & 2 & 4 & 1 & 1 & $\mathrm{Q}_{2}$ \\
\hline 8 & 3 & 5 & 4 & 5 & 1 & 4 & $\mathrm{Q}_{2}$ \\
\hline 9 & 3 & 4 & 2 & 4 & 1 & 3 & $\mathrm{Q}_{2}$ \\
\hline 10 & 2 & 4 & 2 & 4 & 4 & 4 & $\mathrm{~F}_{1}$ \\
\hline 11 & 1 & 2 & 1 & 1 & 3 & 1 & $\mathrm{~F}_{1}$ \\
\hline 12 & 1 & 2 & 1 & 3 & 5 & 3 & $F_{1}$ \\
\hline 13 & 3 & 2 & 1 & 2 & 4 & 2 & $F_{1}$ \\
\hline 14 & 4 & 2 & 1 & 2 & 5 & 3 & $\mathrm{~F}_{2}$ \\
\hline 15 & 4 & 5 & 5 & 5 & 5 & 5 & $\mathrm{~F}_{2}$ \\
\hline
\end{tabular}

\section{B. Diagnostic analysis based on the Improved Petri Nets}

We established a fault tree and improved the Petri net model according to the measurement parameter set, which is based on parameter optimization using overheating fault data 2 as test samples, as shown in Figure 1. The $\mathrm{S}_{1-5}$ are the bottom events, said measuring parameters, introducing the middle event $\mathrm{E}$, which represents the related events change, and $\mathrm{Z}$ as the top event, which represents the target fault, $\mathrm{CH}_{4}, \mathrm{C}_{2} \mathrm{H}_{4}$.
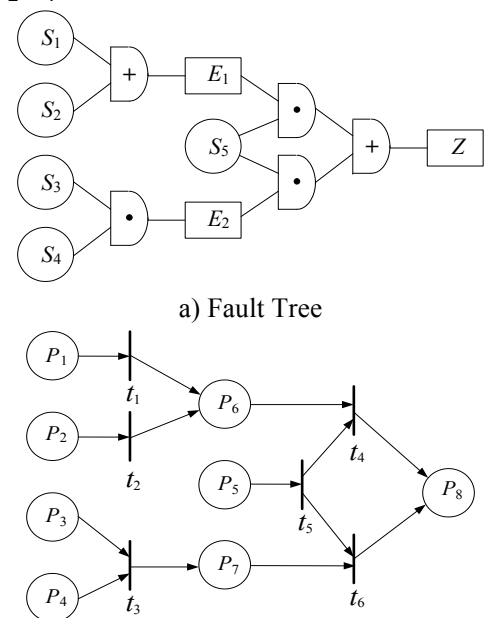

b) Petri Net Model

Figure 1. Fault Tree and Petri Net Model Based on optimized parameters

Diagnostic analysis according to the system shown in Figure $1 \mathrm{~b}$ ) shows that at the moment $\mathrm{t}=0$, signs of the start event are that methane, ethylene and total hydrocarbon are high over the attention value, the Petri net's initial identifications are $\mathrm{M}_{0}=[0,1,1,0,1,0,0,0]$, the change time tag $\mathrm{G}$ is empty, and the incidence matrix of Petri nets is as follows:

$$
\begin{aligned}
& \mathrm{P}_{1}, \mathrm{P}_{2}, \quad \cdots \quad, \mathrm{P}_{8} \\
& \mathrm{t}_{1}\left[\begin{array}{llllllll}
1 & 0 & 0 & 0 & 0 & 1 & 0 & 0
\end{array}\right]^{\mathrm{T}} \\
& \mathrm{t}_{2} \quad \begin{array}{llllllll}
0 & 1 & 0 & 0 & 0 & 1 & 0 & 0
\end{array}
\end{aligned}
$$

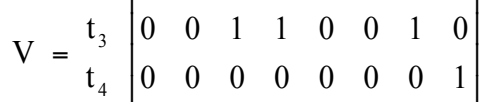

$$
\begin{aligned}
& \mathrm{t}_{5} \quad \begin{array}{llllllll}
0 & 0 & 0 & 0 & 1 & 0 & 0 & 0
\end{array} \\
& \mathrm{t}_{6}\left[\begin{array}{llllllll}
0 & 0 & 0 & 0 & 0 & 0 & 0 & 1
\end{array}\right]
\end{aligned}
$$

According to can-make rules, we calculated the ignition sequence change $U$ based on the initial identification

$$
\mathrm{U}=\left[\mathrm{u}_{\mathrm{i}}\right]=\left[\mathrm{v}\left(\mathrm{P}_{\mathrm{i} 1}, \mathrm{P}_{\mathrm{i} 2}, \cdots\right)\right] 1 \leq \mathrm{i} \leq \mathrm{n}=\left[\begin{array}{llllll}
0 & 1 & 0 & 0 & 1 & 0
\end{array}\right]^{\mathrm{T}}
$$

At this time $t_{2,5}$ ignites, so we calculated the change identification M1 according to formula (4).

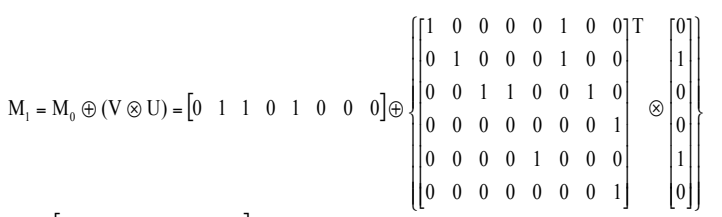$$
=\left[\begin{array}{llllllll}
0 & 1 & 1 & 0 & 1 & 1 & 0 & 0
\end{array}\right]
$$

We added a trigger change to the time stamp set $\mathrm{G}=$ $\left\{\mathrm{t}_{2}(0), \mathrm{t}_{3}(0), \mathrm{t}_{5}(0)\right\}, \mathrm{t}=\mathrm{t}+1$; similarly, change $\mathrm{t}_{4}$ can ignite an ignition change sequence $U=[0,0,0,1,0,0]^{\mathrm{T}}$, add $t_{4}$ to change the time stamp set $\mathrm{G}=\left\{\mathrm{t}_{1}(0), \mathrm{t}_{3}(0), \mathrm{t}_{5}(0), \mathrm{t}_{4}(1)\right\}$, $\mathrm{t}=\mathrm{t}+1=2$, and so on. $\mathrm{M}_{2}=[0,1,1,0,1,1,0,1]$, at the moment $\mathrm{t}=2$, reached the top event, which can make no change. Goal event place $\mathrm{P}_{8}$ exists corresponding to the information from $\mathrm{M}_{2}$, which means system failure. Through a change of the time stamp set $G$, we can detect 
that the transmission of fault is $\mathrm{P}_{2} / \mathrm{P}_{3} / \mathrm{P}_{5} \rightarrow \mathrm{P}_{6} \rightarrow \mathrm{P}_{8}$. The failure condition is that the ontology oil ethylene content is relative high; the local transformer is overheating, whose type is high temperature overheating; and the total amount of hydrocarbon gas increases and the fault aggravates. If the signs of the initial event are ethylene, acetylene and total hydrocarbon, the analysis results are the same. The possible cause of the problem is the lead wire overheating or the drive pipe shunting. Suggestions include core grounding, insulation resistance tests, and dc resistance tests. Lift core checks occur if there are severe cases. The real failure of this sample is the transformer's high temperature overheating. Through spot sampling analysis and a tracking test, we found that gases in oil all have significant growth. $\mathrm{H}_{2}$ changes relatively gently, but hydrocarbon gas content is relatively high. The results of the survey are that the conductive material overheating is caused by the vortex, the lead heats up, and the insulation performance degrades.

\section{CONCLUSIONS}

An improved Petri net model, which is based on a rough set, can identify association rules of multiple attributes implicated in complex systems and can conduct diagnostic analysis of the concurrent and propagation characteristics of fault decision attributes, whose algorithm has parallel reasoning ability. At the same time, it can find all the status values of a system after reasoning. Using the change time tag set we can find a fault propagation path quickly and easily. It perfects the transformer fault diagnosis method on the basis of a traditional Petri network.

\section{REFERENCES}

[1] A. R. G. Castro, and V. Miranda, "Knowledge discovery in neural network with application to transformer failure diagnosis", Power
Systems, Vol. 20, Issue 2, 2005, pp. 717-724. http://dx.doi.org/10.1109/TPWRS.2005.846074

[2] D. Racoceanu, E. Minca, N. Zerhouni. Fuzzy Petri net for monitoring and recovery. IEEE, International Conference on Robotics and Automation, Vol. 2, Issue 3, 2003, pp. 4318-4324. http://dx.doi.org/10.1109/robot.2003.1242268

[3] J.Y. Wang, Y.C. Ji. Application of fuzzy Petri nets knowledge representation in electric power transformer fault diagnosis, Proceeding of the CSEE, 2003,Vol. 23, Issue 1, pp. 121-125.

[4] H. Ren, Z.Q. Mi. Power system fault diagnosis modeling techniques based on encoded Petri nets, Proceedings of CSEE, 2000, VOl. 27, Issue 13, pp.10-14.

[5] J. Sun, S.Y. Qin. A fault diagnosis method for power systems based on Petri nets and probability information, Automation of Electric Power Systems, 2000, Vol. 27, Issue 13, pp. 10-14.

[6] J. Mo, X. Wang. Diagnostic model of insulation faults in power equipment based on Rough Set theory, Proceedings of CSEE, 2004, Vol. 24, Issue 7, pp. 162-167.

[7] J. Y. Wang, Y.C. Ji. Application of Petri nets in transformer fault diagnosis, Power System Technology, 2002, Vol. 26, Issue 8, pp. 21-24.

[8] The State Economic and Trade Commission of the People's Republic of China.DL/T722-2000. Guide in the transformer oil dissolved gas analysis, and judgment. Beijing: China electric power press, 2001.

[9] Electric Power Industry Ministry of the People's Republic of China.DL/T596-1996. Electric power equipment handover and preventive test procedures. Beijing: China electric power press, 2000.

\section{AUTHORS}

Chengyu Sun is with the Jilin Institute of Chemical and Technology, Jilin City, CO 132022 China (e-mail: suncyx@163.com).

XiaoGuang Yue is with the Wuhan University, Wuhan, CO 430072 China (email: xgyue@foxmail.com).

Submitted 21 July 2015. Published as resubmitted by the authors 10 October 2015. 